\title{
Amsterdaml'og \\ Economics of integrating geothermal sources in a district grid heating system
}

Koen Gommers ${ }^{1}$, Marco Bakker ${ }^{2}$

\section{Summary}

After an introduction of Eneco and description of the role for (central) district heating in the Netherlands the presentation will be centered around the economic value of geothermal energy in district heating. The cost of geothermal energy will be compared with the cost of the alternative sources of thermal energy: a gas fired CHP in combination with peak boilers.

With an understanding of the economic drivers in such a project the impact of several economic scenarios for geothermal energy will be assessed. Finally, the integration of geothermal energy in district heating will be compared with a CHPonly district heating system from a $\mathrm{CO}_{2}$-emission perspective.

${ }^{1} 1$ ) Eneco Warmte B.V. Postbus 1950, 3000 BZ Rotterdam,

2) Eneco New Energy, Postbus 1950, 3000 BZ Rotterdam.

Corresponding author: Marco Bakker m.bakker@eneco.nl 